\title{
"In-situ" Observation of Remelting Phenomenon after Solidification of Fe-B Alloy and B-bearing Commercial Steels
}

\author{
Hongbin YIN, Kenneth BLAZEK and Oscar LANZI \\ Process Research, East Chicago (USA) Center, ArcelorMittal Global R\&D, 3001 East Columbus Drive, East Chicago, IN 46312- \\ 2939, U.S.A. E-mail: Hongbin.Yin@arcelormittal.com
}

(Received on April 9, 2009; accepted on June 23, 2009)

\begin{abstract}
It is well known that boron (B) addition to steels can cause difficulties during continuous casting. The difficulty includes surface cracks, internal half-way cracks as well as centerline problems on the cast products. In severe cases, a breakout can occur during casting of B-bearing steels. According to the studies of the effect of boron on the pseudo-binary phase diagrams of Fe-B alloys at various carbon levels by the authors, it was found that the addition of boron introduces the possibility of steel initially completely solidifying followed by a retrograde melting phenomenon in all $\mathrm{C}$ contents below $1 \%$. This retrograde melting phenomenon will most likely occur at interdendritic regions and grain boundaries at temperatures approaching $1350^{\circ} \mathrm{C}$. The remelt liquid will be retained down to temperatures approaching $1100^{\circ} \mathrm{C}$. The retention of this low melting point phase during casting is believed to be the primary cause of casting difficulties of the Bbearing commercial products.

In order to confirm the modeling study of the phase diagrams and the finding of the remelting phenomenon, Confocal Scanning Laser Microscope (CSLM) studies were carried out for "in-situ" observation. These studies not only confirmed the existence of the retrograde-melting phenomenon at temperatures below $1200^{\circ} \mathrm{C}$, but also revealed that severe segregation of B in steel could cause the existence of liquid phase down to at least $1350^{\circ} \mathrm{C}$ even in steels bearing as little as $10 \mathrm{ppm}$ B. The present paper will summarize the observation results.
\end{abstract}

KEY WORDS: boron steel; retrograde melting; metatectic reaction; solidification; Confocal Scanning Laser Microscopy; continuous casting.

\section{Introduction}

The current steel market for the automobile industry is moving towards a larger fraction of applications of Advanced High Strength Steels (AHSS). One of the advantages of the AHSS is its high strength so that the automobile components can be made at a thinner gauge (lighter weight) without sacrificing safety. Due to the marked effect of boron on strengthening of steel, a series of boron-bearing steels (B-steels) have been developed and commercially applied to many new and future automobile models. In addition to the increasing demand for B-steels in the automobile industry, the traditional market of high hardenability Bsteel continues to grow. However, during commercial production of the B-steels, challenges are always brought to the steelmaking processes, especially during the continuous casting process. The difficulties include frequent casting breakouts, surface cracking and internal cracking problems in as-cast slabs for both conventional and thin slab casting.

An example given in the upper part of Fig. 1 is the photo of a longitudinal cross section of an as-cast product with severe internal half-way cracks from a thin slab caster at ArcelorMittal USA. The B content of the heat chemistry is 24 ppm. The lower part of Fig. 1 is the photo of a magnified cracking area after etching. It is clear that the crack is caused by inter-dendritic hot cracking phenomenon. From the length of the cracks and temperature gradient in the slab during casting, it is expected that an extremely low melting point liquid film exists in-between the columnar dendrites. When deformation of the thin slab occurs at later stage of

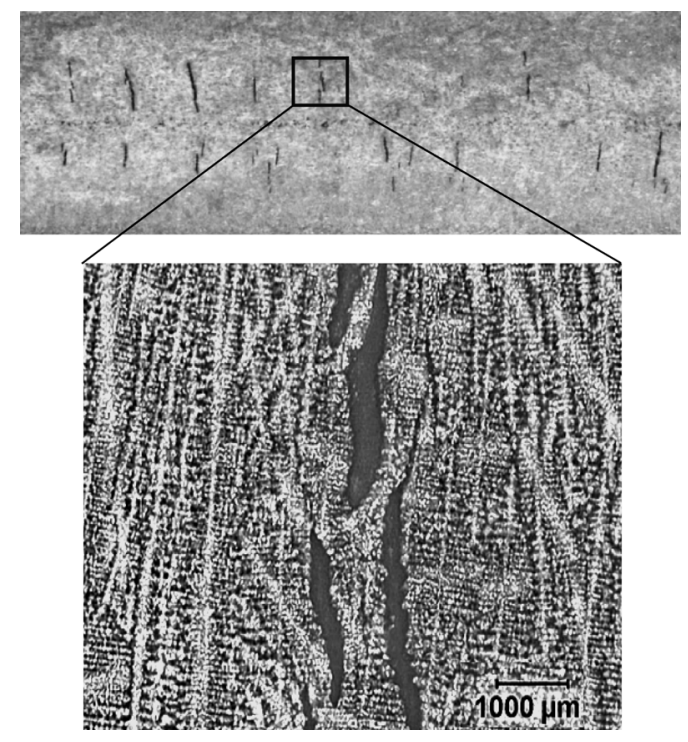

Fig. 1. Half-way crack in thin slab of B steel. 
the caster, these interdendritic areas with liquid film can be opened because of their zero strength.

In order to understand the source cause of the problems that B brings to the casting process, an extensive study was carried out at the East Chicago (USA) Center of ArcelorMittal Global R\&D. The Thermo-Calc software package was utilized to determine the phase diagrams of pseudo-binary $\mathrm{Fe}-\mathrm{B}$ system at various boron and carbon ranges. These modeling analyses discovered a phenomenon specific to the $\mathrm{Fe}-\mathrm{B}$ alloy system in that a metatectic reaction and a post-metatectic retrograde melting occur after solidification upon cooling to low temperatures down to $1100^{\circ} \mathrm{C}$. These processes cause B-rich liquid to form on cooling, interrupting the normal solidification process. After this modeling work, experimental studies were carried out to confirm the retrograde melting phenomenon with lab made $\mathrm{Fe}-\mathrm{C}-\mathrm{B}$ alloys and commercially made B-steels.

One of the techniques utilized in this study was the "insitu" observation with a Confocal Scanning Laser Microscope (CSLM). The CSLM has been developed and widely used in "in-situ" observations of high temperature phenomena of steel during phase transitions, melting and solidification. $^{1-4)}$ It is an ideal tool for observing the retrograde melting for visual confirmation of the phenomenon.

In this paper, the modeling work will be briefly reviewed and the "in-situ" observation results will be presented in detail.

\section{Thermodynamic Phase Analysis}

Based on ThermoCalc calculations, the phase diagrams for the Fe-B system were developed for $0,0.05,0.1,0.2$, $0.4,0.6,0.8$ and $1.0 \%$ carbon contents with boron varying from 0 to $0.1 \%$. Three additional pseudo-binary phase diagrams for the $\mathrm{Fe}-\mathrm{B}$ system were developed for $0,0.3$ and $0.8 \%$ carbon contents with $0.4 \% \mathrm{Mn}$ and $0.27 \% \mathrm{Si}$ and the boron contents varying over the same range.,6)

\subsection{Pure Fe-B system}

For pure Fe-B alloy as seen in Fig. 2, a metatectic reaction will occur at $1360^{\circ} \mathrm{C}$ when $\mathrm{B}$ content is between 0.022 to $0.045 \% \mathrm{wt}$. The result of this reaction is the $\delta$ ferrite phase transforming into $\gamma$ austenite and liquid. The liquid phase remains until the temperature reaches $1175^{\circ} \mathrm{C}$, which closely matches the $1177^{\circ} \mathrm{C}$ reported by Kubaschewski. ${ }^{7)}$ The interesting point here is that the steel will first fully solidify upon cooling and then partially remelt at a lower temperature of $1360^{\circ} \mathrm{C}$. This is a metatectic reaction.

A more interesting phenomenon found in this phase diagram is the retrograde melting line that bends towards the left side as temperature decreases. As shown by the dashed line in Fig. 2, when temperature decreases, the steel fully solidifies at around $1500^{\circ} \mathrm{C}$. After a series of phase transformations into the full $\gamma$ region, it meets the retrograde melting line at around $1240^{\circ} \mathrm{C}$ below which the liquid steel reappears. This portion of liquid will finally solidify at $1175^{\circ} \mathrm{C}$. This liquid is boron-rich and forms on cooling because the solubility of B in the solid is decreasing. The importance of the retrograde melting phenomenon is that it moves the remelting of steel towards even lower B content from $0.022 \%$ of the metatectic reaction starting point to

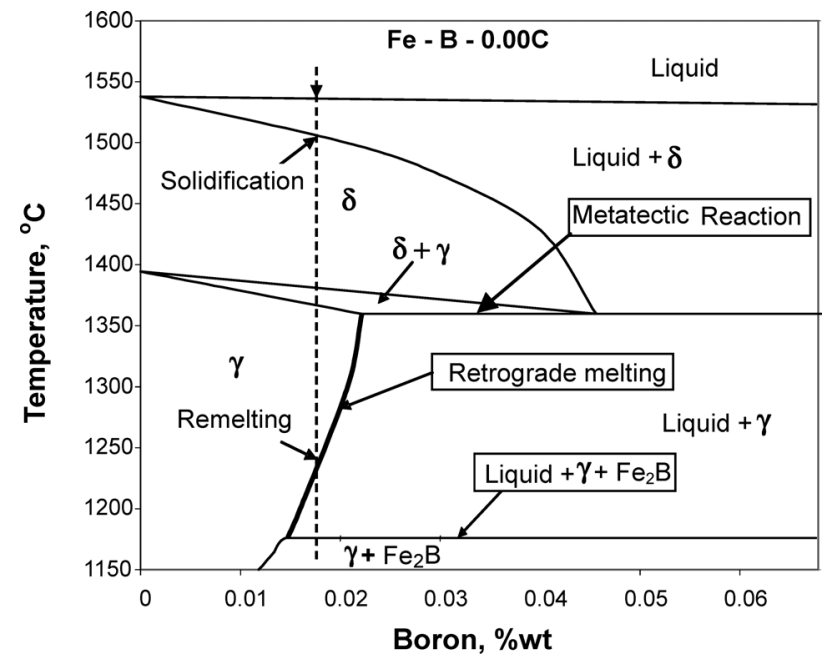

Fig. 2. Fe-B phase diagram from ThermoCalc.

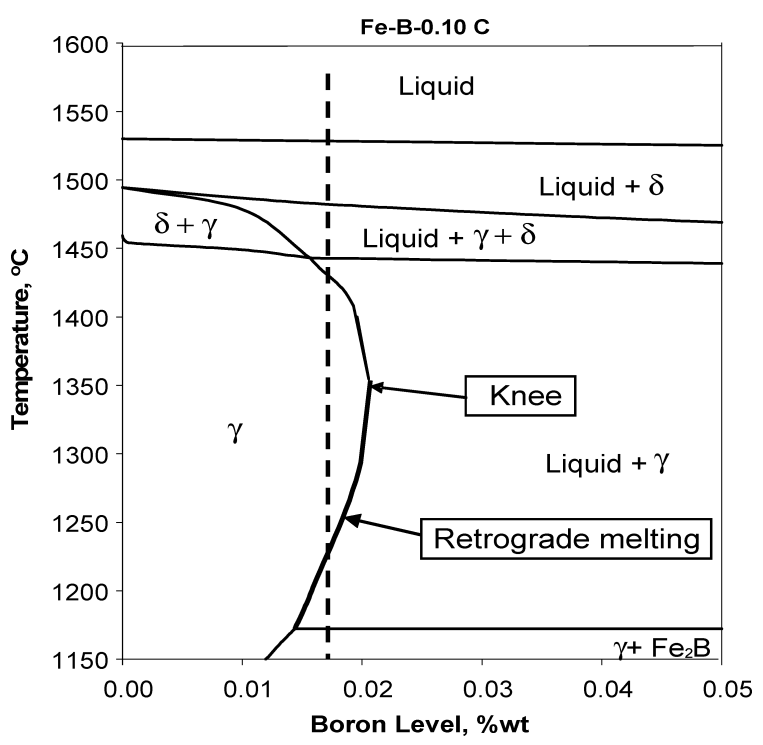

Fig. 3. $\mathrm{Fe}-\mathrm{B}-0.1 \% \mathrm{C}$ phase diagram from ThermoCalc.

$0.015 \%(150 \mathrm{ppm})$ near the lower end of the retrograde melting curve.

It is well known that the segregation of B during steel solidification is significant. For steel containing boron below $30 \mathrm{ppm}$, the segregation will easily increase the B content to exceed $150 \mathrm{ppm}$ at local spots, such as interdendritic areas and grain boundaries, at the cooling rate of conventional and thin slab casting.

\subsection{Fe-B-C and Fe-B-C-Mn-Si System}

For commercial steel grades, $\mathrm{C}, \mathrm{Mn}$ and $\mathrm{Si}$ are normally added to achieve required properties and these elements typically have a strong influence on the phase transitions of iron. Hence, pseudo-binary phase diagrams for the Fe-B system were developed by adding $\mathrm{C}, \mathrm{Mn}$ and $\mathrm{Si}$. An example is given in Fig. 3 for $\mathrm{Fe}-\mathrm{B}-0.1 \% \mathrm{C}$. For other $\mathrm{Fe}-\mathrm{B}-\mathrm{C}$ phase diagrams developed by the authors, please refer to Ref. 5).

Adding $\mathrm{C}$ into the $\mathrm{Fe}-\mathrm{B}$ system will change the $\mathrm{Fe}-\mathrm{B}$ alloy system significantly in the high temperature region of the phase diagram, shrinking the fully solid area into a lower B content region. Instead of the metatectic reaction, 


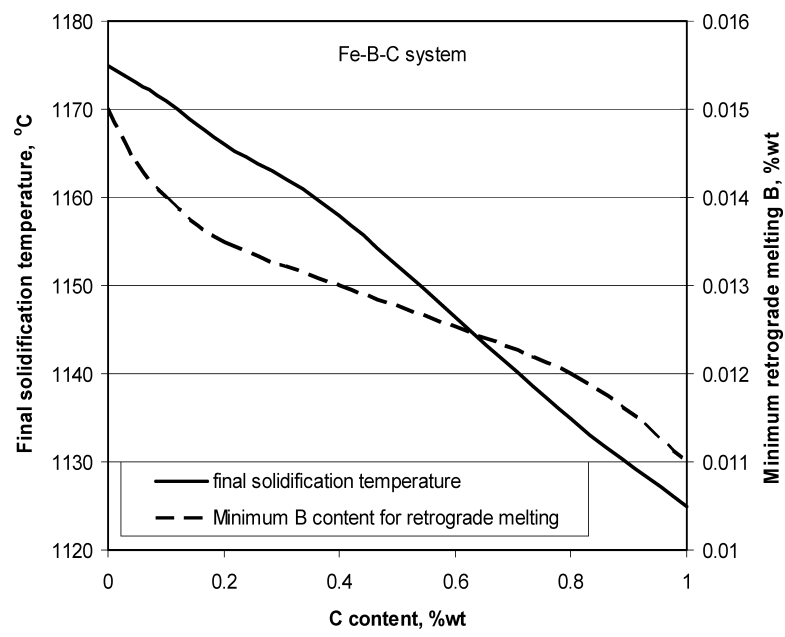

Fig. 4. Final solidification temperature and minimum $\mathrm{B}$ content for retrograde melting in $\mathrm{Fe}-\mathrm{B}-\mathrm{C}$ system.

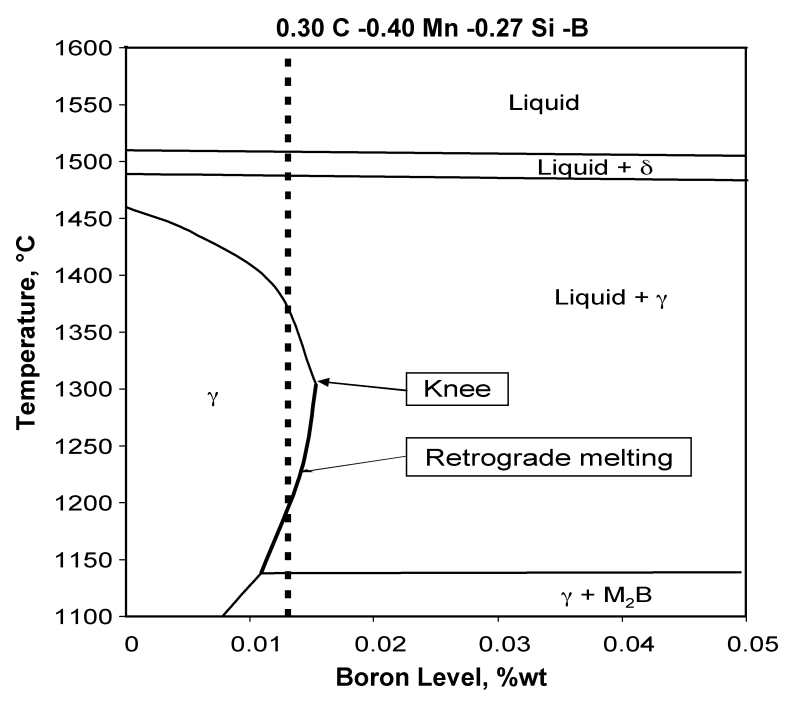

Fig. 5. Fe-B-C-Mn-Si phase diagram from ThermoCalc.

the $\mathrm{Fe}-\mathrm{B}-\mathrm{C}$ system develops a knee below which retrograde remelting occurs at similar temperature to that for the pure $\mathrm{Fe}-\mathrm{B}$ system of around $1350^{\circ} \mathrm{C}$. The retrograde melting remains for $\mathrm{C}$ contents up to approximately $1 \%$. When $\mathrm{C}$ increases, the minimum boron content for the retrograde melting phenomenon decreases and the final solidification temperature is simultaneously reduced as seen in Fig. 4. For example, at $\mathrm{C}$ content of $0.8 \%$, the minimum $\mathrm{B}$ content to induce the retrograde melting phenomenon is reduced to about $120 \mathrm{ppm}$ from $150 \mathrm{ppm}$ at $0 \% \mathrm{C}$. In the meantime, the final solidification point decreases to $1135^{\circ} \mathrm{C}$ from $1175^{\circ} \mathrm{C}$ at $0 \% \mathrm{C}$.

Adding fixed amounts of $\mathrm{Mn}$ and $\mathrm{Si}$ can further alter the phase diagram and an example is shown in Fig. 5 for $\mathrm{Fe}-\mathrm{B}-0.3 \% \mathrm{C}-0.4 \% \mathrm{Mn}-0.27 \% \mathrm{Si}$ system. However, the knee and the retrograde melting are still there. As $\mathrm{C}$ content increases, both the minimum boron content for the remelting and the final solidification temperature decrease as shown in Fig. 6. By comparing Fig. 4 and Fig. 6, it becomes clear that the addition of $\mathrm{Mn}$ and Si makes the minimum boron content for the retrograde melting and the final solidification temperature both decrease quite markedly. As

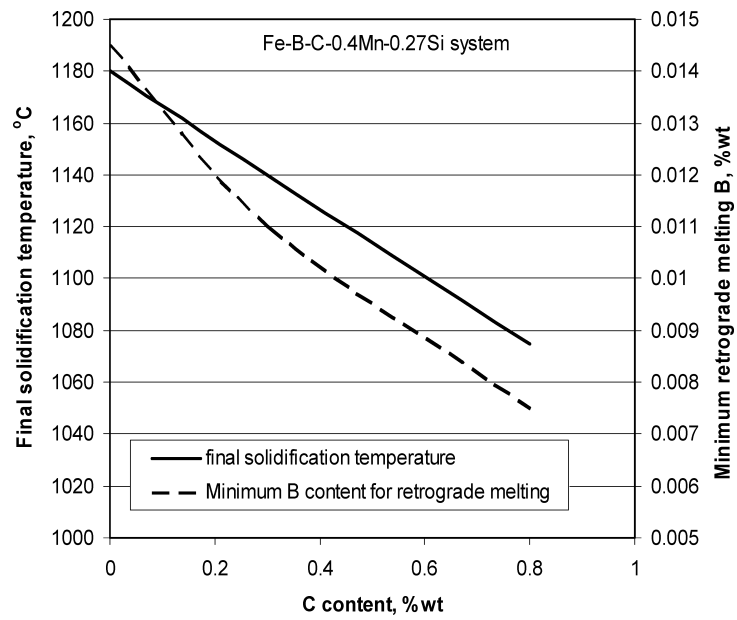

Fig. 6. Final solidification temperature and minimum B content for retrograde melting in $\mathrm{Fe}-\mathrm{B}-\mathrm{C}-\mathrm{Mn}-\mathrm{Si}$ system.

can be seen that at $0.8 \% \mathrm{C}$, the final solidification point is below $1080^{\circ} \mathrm{C}$ and the minimum $\mathrm{B}$ content to reach retrograde melting is at $75 \mathrm{ppm}$ only.

This implies that the addition of common elements in steel will further decrease the B content at which the retrograde melting phenomenon will start. Under strong segregation conditions, B content at inter-dendritic area can easily pass this threshold and as a result, retrograde melting occurs in as-cast products that can cause internal defects as shown in Fig. 1.

However, these conclusions are from modeling analyses only based on ThermoCalc calculations. Experimental confirmation needs to be obtained to confirm the retrograde melting phenomenon.

\section{Experiments}

\subsection{CSLM System}

One of the tools utilized in the present study is the CSLM, which has been widely used for "in-situ" observation of steel phase transitions at elevated temperatures up to the melting of steels. The distinction between solid and liquid phases at microscopic scale can be made easily with the CSLM.

The CSLM combined with an infrared image furnace is schematically illustrated in Fig. 7 as described elsewhere in more detail. $\left.{ }^{8}\right)$ The observed steel melting-solidification behavior was displayed on a CRT monitor at a magnification of up to $2100 \times$ and simultaneously recorded on a videotape at a rate of 30 frames per second. The resolution of the CSLM was $c a$. $0.5 \mu \mathrm{m}$, which is the minimum size of a feature detectable by the CSLM.

The steel sample was machined into a disc $(3.8 \mathrm{~mm}$ diameter $\times 3 \mathrm{~mm}$ height) with the observed side mirror polished, and set into a high purity alumina crucible $(5.5 \mathrm{~mm}$ outer dia., $4.5 \mathrm{~mm}$ inner dia. $\times 5 \mathrm{~mm}$ height). The sample and crucible were placed into the Gold Image Furnace at one focal point of the gold plated ellipsoidal chamber as shown in Fig. 7. Then, alternating operation between high vacuum and high purity Ar flush was made three times to the furnace chamber to desorb residual gases from all internal surfaces of the chamber. Then, a final Ar flush of 


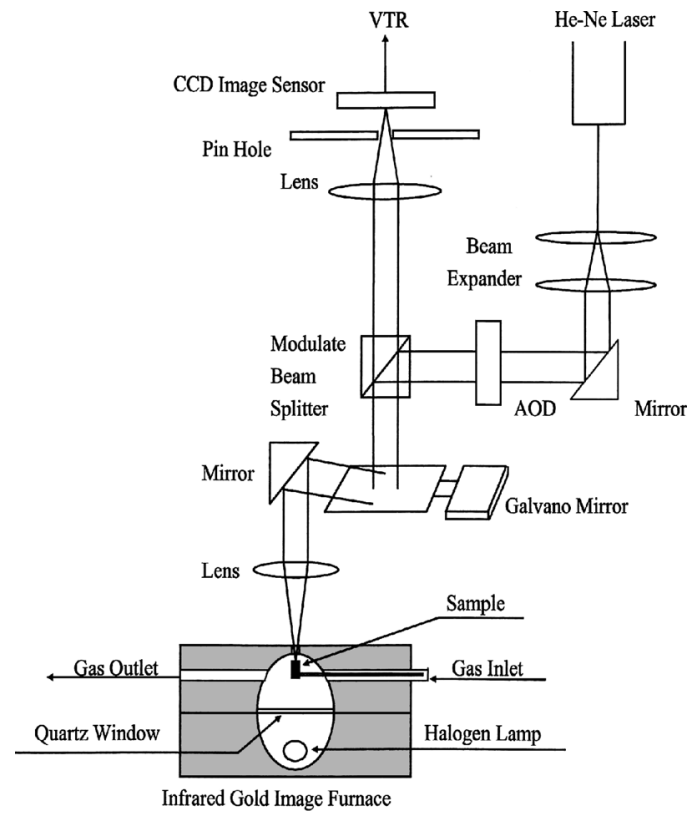

Fig. 7. Schematic diagram of confocal scanning laser microscope with infrared gold image furnace.

Table 1. Lab heat chemistries.

\begin{tabular}{|c|c|c|c|c|}
\hline Sample & $\mathrm{C}, \mathrm{w} / \mathrm{o}$ & $\mathrm{Mn}, \mathrm{w} / \mathrm{o}$ & $\mathrm{Si}, \mathrm{w} / \mathrm{o}$ & $\mathrm{B}, \mathrm{w} / \mathrm{o}$ \\
\hline$\overline{1}$ & 0.0035 & 0.404 & 0.268 & 0.0094 \\
\hline 2 & 0.0019 & 0.389 & 0.285 & 0.0215 \\
\hline 3 & 0.0016 & 0.435 & 0.282 & 0.0307 \\
\hline 4 & 0.0013 & 0.412 & 0.278 & 0.0395 \\
\hline 5 & 0.0025 & 0.41 & 0.271 & 0.0477 \\
\hline 6 & $0 . .2863$ & 0.404 & 0.286 & 0 \\
\hline 7 & 0.2966 & 0.397 & 0.27 & 0.004 \\
\hline 8 & 0.2941 & 0.423 & 0.291 & 0.0107 \\
\hline 9 & 0.2973 & 0.415 & 0.276 & 0.0196 \\
\hline 10 & 0.8174 & 0.398 & 0.274 & 0.0038 \\
\hline 11 & 0.8322 & 0.404 & 0.277 & 0.0093 \\
\hline 12 & 0.847 & 0.0419 & 0.285 & 0.0191 \\
\hline 13 & 0.0015 & 0.415 & 0.271 & 0 \\
\hline 14 & 0.002 & 0.394 & 0.263 & 0.0004 \\
\hline 15 & 0.0018 & 0.414 & 0.279 & 0.0015 \\
\hline 16 & 0.0022 & 0.411 & 0.275 & 0.0048 \\
\hline 17 & 0.3102 & 0.392 & 0.267 & 0.0008 \\
\hline 18 & 0.307 & 0.381 & 0.265 & 0.0014 \\
\hline 19 & 0.7628 & 0.374 & 0.266 & 0 \\
\hline 20 & 0.782 & 0.377 & 0.263 & 0.0007 \\
\hline 21 & 0.7394 & 0.382 & 0.267 & 0.0011 \\
\hline 22 & $0.228 *$ & 1.194 & 0.25 & 0.004 \\
\hline 23 & $0.2222^{*}$ & 1.176 & 0.245 & 0.0042 \\
\hline 24 & $0.2367 \#$ & 1.204 & 0.218 & 0.0023 \\
\hline 25 & $0.2421 \#$ & 1.216 & 0.217 & 0.0023 \\
\hline
\end{tabular}

30 min follows to minimize any oxygen inside the chamber. During the experiment, ultra pure argon gas containing $c a$. $10 \mathrm{ppb}$ of combined $\mathrm{CO}+\mathrm{CO}_{2}+\mathrm{H}_{2} \mathrm{O}+\mathrm{O}_{2}$ was further deoxidized with $\mathrm{Cu}$ and $\mathrm{Mg}$ powder at elevated temperatures and introduced into the chamber to prevent the sample surface from reoxidation. The sample was subsequently heated manually to desired temperatures by the halogen lamp $(650 \mathrm{~W})$ located at the other focal point of the furnace. Once the temperature of sample reached a desired value, observations were made within the range of $\pm 1{ }^{\circ} \mathrm{C}$ around the controlled value by an advanced computer control of heating power input. Cooling of the sample was also done manually.

\section{2. $\mathrm{Fe}-\mathrm{B}-\mathrm{C}-\mathrm{Mn}-\mathrm{Si}$ Alloy Lab Heats}

For the confirmation of the retrograde melting phenomenon, 21 lab heats (1 to 21 in Table 1) with varied B and C but fixed $\mathrm{Mn}$ and $\mathrm{Si}$ were made. In addition, 4 more lab heats (22 to 25 in Table 1) were made to simulate two commercial grades 1523B (*) and 1525B (\#) which are being produced at ArcelorMittal USA slab casters. In both simulated commercial steel grades, the $\mathrm{Al}$ and Ti were both controlled at $0.04 \%$. There was no $\mathrm{Cr}$ in $1523 \mathrm{~B}$ whereas $0.22 \% \mathrm{Cr}$ was added in $1525 \mathrm{~B}$. No other element was put in for these lab heats. As can be seen in Table 1, the C varies from 0.0013 to $0.847 \%$ and $\mathrm{B}$ changes in the range from 0 to $0.0477 \%$. These lab heats were made with a $50 \mathrm{~kg}$ vacuum induction furnace and ingots were cast inside the furnace. Then, samples were machined out of the subsurface area of the ingots for CSLM studies.

\section{Results}

\subsection{Observation upon Cooling}

The significance of the present modeling work was the finding of the low melting point phase that could exist below $1200^{\circ} \mathrm{C}$ in $\mathrm{Fe}-\mathrm{B}(-\mathrm{C}-\mathrm{Mn}-\mathrm{Si})$ alloys. To confirm, CSLM observations were made by melting the samples first and solidifying them with subsequent cooling. The difficulties faced in these experiments were the control of the melting and solidification process. In most cases, the samples either melted too quickly and the liquid surface turned into a dome due to surface tension or they solidified too fast and the surface became too rough by the formation of dendrites. Therefore, the observation during cooling became impossible for the finally solidified, alloying element enriched center area of the samples.

The observations on a few successful cases however easily confirmed the existence of the low melting phase. An example is given here in Fig. 8 for Sample \#3 during cooling. As can be seen in Fig. 8(A) at $25 \mathrm{~min}$ and $40 \mathrm{~s}$ of the experiment, a liquid steel film remains at $1179^{\circ} \mathrm{C}$. As temperature decreases, the liquid volume starts to diminish and the liquid film turns to localized droplets on the surface (Fig. 8(B)). At $1026^{\circ} \mathrm{C}$ at $25: 55$, only one small droplet is left in Fig. $8(\mathrm{C})$ and it eventually solidifies a second later at $1011^{\circ} \mathrm{C}$ in Fig. 8(D). During this experiment, the cooling rate was set fast and some degree of undercooling could not be avoided. In this case, about $100^{\circ} \mathrm{C}$ undercooling was seen if compared with the model-calculated value in Fig. 6.

\subsection{Observation upon Heating}

Due to the difficulties during cooling, the observations during heating were utilized as the primary evidence to confirm the retrograde melting and metatectic reaction. A sign of the existence of the retrograde melting phenomenon is the appearance of liquid phase during heating at lower temperatures and then the liquid phase solidifying as temperature increases further. Such a reverse process would also rule out low-melting inclusions such as borates, which would not re-solidify on heating. If the solidification during heating happens quickly with an obvious solid phase transformation, it will be the evidence of a metatectic reaction.

A freshly polished sample has a flatter and clean surface 

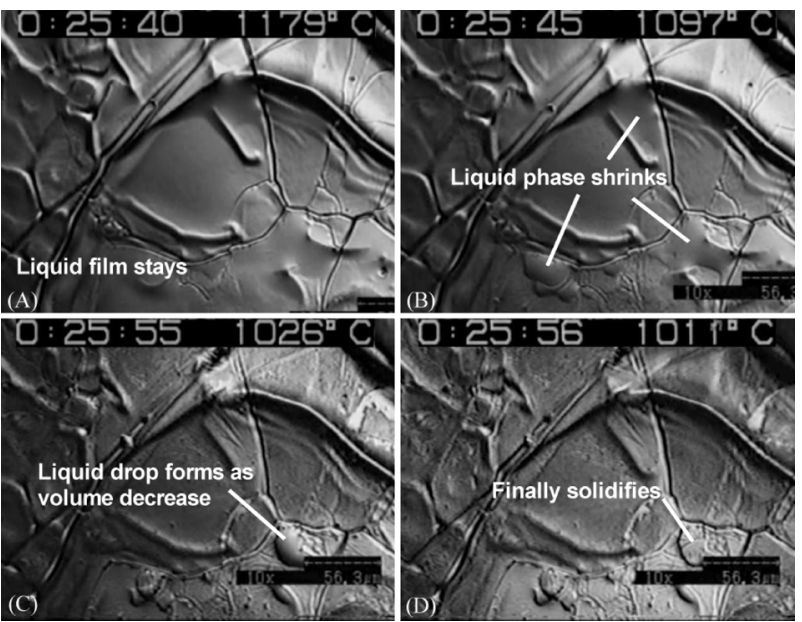

Fig. 8. Observation of B steel solidifying at very low temperature (below $1200^{\circ} \mathrm{C}$ ) during cooling.
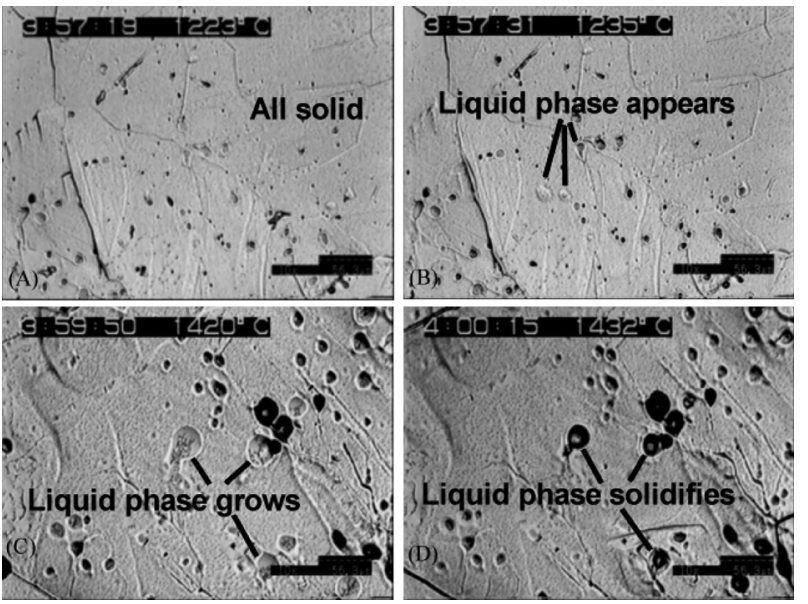

Fig. 9. Observation of $B$ steel melting at low temperature and solidifying at higher temperature on heating of Sample \#4.

which makes the observation during heating much easier, despite the fact that the solid phase change can increase the surface roughness. The real advantage of using freshly polished samples on heating is that the samples maintain the as-cast structure and segregation levels as when they were cast. This feature makes the observation more realistic when compared to actual casting.

One example shown in Fig. 9 to demonstrate the observed phenomenon in time sequence is from the observation on Sample \#4 during heating. At $1233^{\circ} \mathrm{C}$ in Fig. 9(A), the surface is all solid. Twelve seconds later in Fig. 9(B), some liquid phase droplets appear on sample surface. The spacing between adjacent droplets is around 10 to $20 \mu \mathrm{m}$, which is equivalent to the scale of secondary dendrite arm spacing. As temperature continuously rises, more and more liquid comes out from the solid substrate (see Fig. 9(C) at $1420^{\circ} \mathrm{C}$ ). These liquid droplets solidify simultaneously as an observed solid phase transition occurs in Fig. 9(D) at $1432^{\circ} \mathrm{C}$. Therefore, the observed phase change is clearly the metatectic reaction.

Another example is given in Fig. 10 from the observation of Sample \#3 on heating. At 22:13 in Fig. 10(A) when temperature rises to $1192^{\circ} \mathrm{C}$, the entire sample surface is still
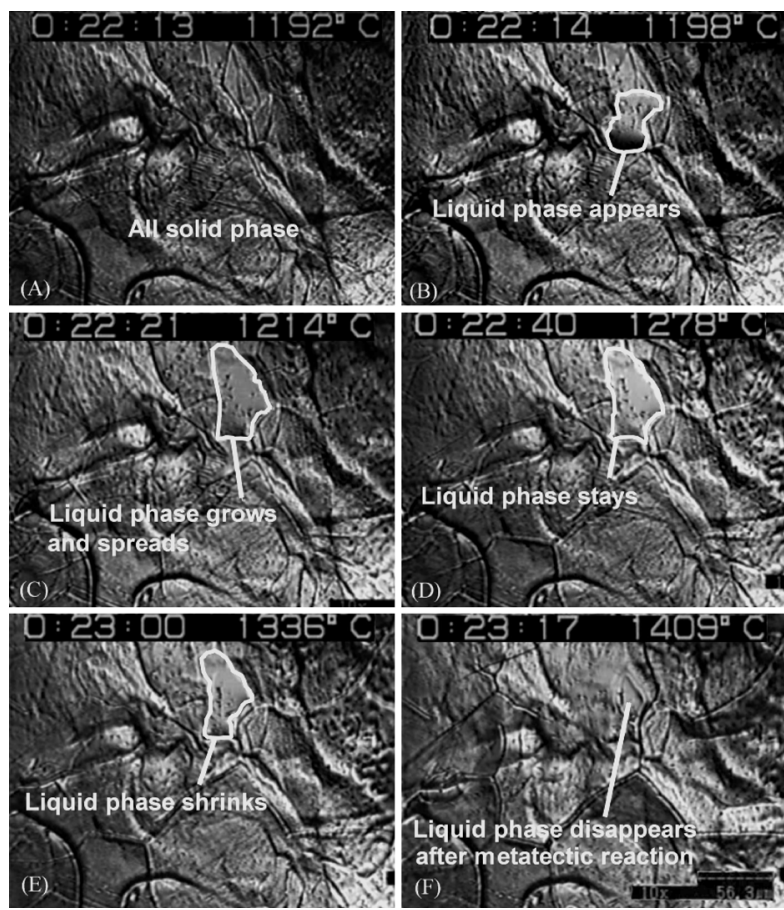

Fig. 10. Observation of $B$ steel melting at low temperature and solidifying at higher temperature on heating of Sample \#3.

solid. One second later as the temperature reaches only $1198^{\circ} \mathrm{C}$, liquid phase appears and forms a droplet as shown in the circle of white line in Fig. 10(B). The volume of the liquid phase increases while the droplet spreads out as temperature continues to rise to $1214^{\circ} \mathrm{C}$ in Fig. $10(\mathrm{C})$. Then, the liquid volume remains constant until the temperature reaches $1336^{\circ} \mathrm{C}$ in Fig. $10(\mathrm{E})$, at which point the liquid starts to shrink. At $1409^{\circ} \mathrm{C}$, after the drastic metatectic reaction (see the new grain boundaries formed after the reaction), the liquid disappears suddenly (see Fig. 10(F)). The observed phase change phenomena follow exactly as predicted by the ThermoCalc calculated phase diagram in Fig. 2 , although the temperatures are not matching. This is due apparently to the fact that the phase diagram is done under equilibrium condition whereas the CSLM experiment has superheating when the sample is heated rapidly and the controlled furnace temperature is not the true sample surface temperature.

\subsection{Observation Summaries}

By reviewing all the observations recorded on video tapes, the observed temperatures at which phase transformation and phase appearance/disappearance occurred were marked down and plotted over the ThermoCalc generated phase diagrams. The example shown in Fig. 11 is to compare the phase diagram and the observations for the $\mathrm{Fe}-\mathrm{B}$ alloy with $0 \% \mathrm{C}-0.4 \% \mathrm{Mn}-0.27 \% \mathrm{Si}$ listed in Table 1 . Note that the marked temperatures are from both cooling (symbols with circles) and heating (symbols without circles) observations during CSLM experiments.

For all boron contents higher than $0.0215 \%$ in Fig. 11, a low melting point $\mathrm{Fe}-\mathrm{B}$ liquid phase forms from 1000 to $1200^{\circ} \mathrm{C}$. This liquid disappears between 1277 and $1460^{\circ} \mathrm{C}$ due to the metatectic reaction for $\mathrm{B}$ contents between 


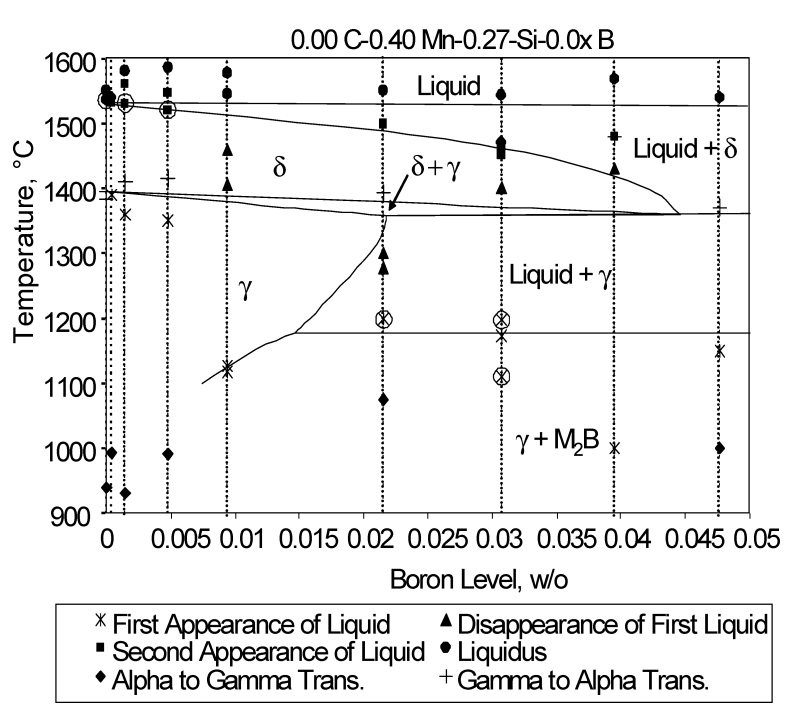

Fig. 11. Graphical Representation of CSLM results.

0.0215 and $0.0395 \%$, but it does not occur for the $0.0477 \%$ boron alloy since it is past the metatectic region, all as ThermoCalc predicted.

The low melting point Fe-B liquid appears also for all boron contents less than $0.0150 \%$, below which the equilibrium phase diagram predicts that this liquid phase will not exist. The lowest boron level at which the low melting point liquid was observed was $4 \mathrm{ppm}$ and it was also observed for the 15 and 48 ppm boron levels as well as the $94 \mathrm{ppm}$ level. This liquid appeared between 1350 and $1390^{\circ} \mathrm{C}$ for the 4 to $48 \mathrm{ppm}$ boron levels and at about $1120^{\circ} \mathrm{C}$ for the $94 \mathrm{ppm}$ boron level. The appearance of a liquid at such a low temperature was not predicted by the ThermoCalc pseudo-binary phase diagram. Therefore, its existence can only be attributed to segregation of boron during solidification. It can be concluded for $0 \%$ carbon level that the ThermoCalc prediction of the phase diagram is accurate and that even with very minor boron additions of 4 ppm or more a low melting point, iron-boron liquid phase will exist at low temperatures due to segregation at solidification.

It is apparent from the observation of these alloys under the confocal microscope that the volume of the casting occupied by this low melting point phase decreases as the boron content decreases and the temperature at which it disappears increases.

The same summaries were done for $0.3 \% \mathrm{C}$ and $0.8 \% \mathrm{C}$ alloy systems and similar conclusions can be obtained.

\section{Discussions}

In Fig. 12, all observations on the first liquid phase (lowest melting point) appearance are plotted together for all alloy systems studied with $0 \% \mathrm{C}, 0.3 \% \mathrm{C}$ and $0.8 \% \mathrm{C}$. The lines with no symbols are the calculated temperatures at which the first liquid should appear based on the ThermoCalc generated phase diagrams; the lines with symbols are the corresponding observed temperatures. The step change represents the $\mathrm{B}$ level above which the low melting point phase starts to appear.

In principle, the steps are observed for all three $\mathrm{C}$ alloy levels studied and the shifting trend of the step temperature

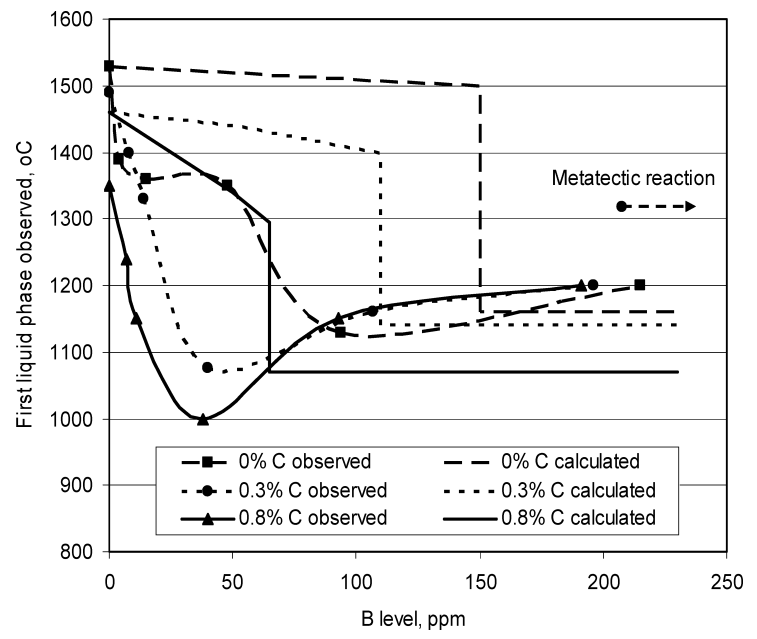

Fig. 12. Comparison of observed and calculated temperatures at which the first liquid phase appears.

and step B content varying with $\mathrm{C}$ levels agrees well with the prediction. However, the step B contents are much lower for the observed cases than the calculated ones. For $0.3 \%$ and $0.8 \% \mathrm{C}$, observed the step is between 10 to $40 \mathrm{ppm}$ of $\mathrm{B}$, but the prediction shows 110 and $65 \mathrm{ppm}$ respectively. For $0 \% \mathrm{C}$, there seems to be two steps. The low step B content is between 50 to $90 \mathrm{ppm}$ compared with $150 \mathrm{ppm}$ predicted. The reason for these observed lower step B contents compared with model-calculated values is believed to be the segregation of B during solidification, which induces local enrichment of B in-between dendrites or grain boundaries.

At B contents even lower than the primary steps of Fig. $12(\mathrm{~B}<10 \mathrm{ppm})$, the observed slopes of the temperature as a function of $\mathrm{B}$ content are much steeper than the predicted ones for all $\mathrm{C}$ systems. For $0 \% \mathrm{C}$ system, there is a plateau of first liquid appearing temperature at B between 20 to $50 \mathrm{ppm}$. This temperature is very close to the metatectic reaction temperature at which the predicted B content from ThermoCalc should be in between 220 and $450 \mathrm{ppm}$. All of these observations also indicate that the $\mathrm{B}$ segregation causes these shifts.

According to the modified Scheil-Gulliver model calculation which is also available in ThermoCalc (with B and $\mathrm{C}$ specified as interstitial elements that are therefore equilibrated between phases), the B segregation in the final liquid is 10-15 times higher in the $0 \% \mathrm{C}$ composition (but additional segregation might occur with retrograde melting, which the Scheil-Gulliver calculation did not capture). It was $70-80$ times higher in the $0.3 \%$ and $0.8 \% \mathrm{C}$ compositions, where final solidification was calculated only at $1120^{\circ} \mathrm{C}$ because of the presence of low-melting, B-rich liquid. In Fig. 12, it can be estimated that the segregation level in the lab ingot is about 10 times, which is reasonable by considering the fast cooling rate in the small $50 \mathrm{~kg}$ rectangular ingot. A low voltage SEM semi-quantitative analysis on a high B sample showed a ratio of $5^{9)}$ from B concentrated area to surrounding matrix, which is in the same order of magnitude as estimated from Fig. 12. For thin slab casting, the slab cooling rate near the surface of the cast slab should be higher than the small lab ingot and hence the segregation level can be even greater. Defects have been 
found in the thin slab sample shown in Fig. 1 which only contains $24 \mathrm{ppm} \mathrm{B}$. The formation of these defects requires a segregation level of about 20 times the base composition to form the liquid melting phase found in the ThermoCalc phase diagram for the alloy. Since the sample in Fig. 1 is a 1523 grade with $0.23 \% \mathrm{C}$, the $70-80 \mathrm{x}$ maximum segregation predicted by the Scheil-Gulliver calculation for high $\mathrm{C}$ levels applies, and the segregation required to produce the defect falls under this limit.

At this level of segregation even very low B content may lead to retrograde melting, metatectic reaction, and formation of low-melting liquid in B steels during thin slab continuous casting. This is the reason that the casting of B steel becomes difficult with possibility of a breakout, hot shortness, surface cracks as well as the internal hot cracking defect shown in Fig. 1.

\section{Conclusions}

(1) Thermodynamic analysis showed that the addition of boron to steel introduces the possibility of steel initially completely solidifying and then partially remelting (retrograde melting and a metatectic reaction), which will most likely occur at grain boundaries and inter-dendritic regions. The liquid can be maintained down to a temperature of between 1120 and $1170^{\circ} \mathrm{C}$.

(2) "In-situ" observations made with the Confocal Scanning Laser Microscope confirmed the retrograde melting and metatectic reaction phenomena in $\mathrm{B}$ containing steel alloys at different $C$ levels.

(3) Due to the significance of boron segregation at grain boundaries and interdendritic regions, a low melting point iron-boron phase appears much earlier than the predicted temperature at bulk boron contents as low as $0.0004 \%$.

(4) This phenomenon was found to lead to severe internal defects on commercial continuous cast product with only 20 ppm of boron. It is highly likely that even the lowest boron additions of less than $10 \mathrm{ppm}$ can cause cast defects based on the observations from the present study. Further additions of boron will only increase the severity of defects.

\section{Acknowledgement}

The authors would like to thank the Center for Iron and Steel Research at Carnegie Mellon University, USA, for providing the CSLM equipment and operation support for this study.

\section{REFERENCES}

1) H. Yin, T. Emi and H. Shibata: Acta Mater, 47 (1999), 1523.

2) H. Yin and T. Emi: Metall. Mater. Trans. B, 34B (2003), 483.

3) H. Shibata, H. Yin, S. Yoshinaga, T. Emi and M. Suzuki: ISIJ Int., 38 (1998), 149.

4) H. Yin, H. Shibata, T. Emi and M. Suzuki: ISIJ Int., 37 (1997), 946.

5) K. Blazek, O. Lanzi and H. Yin: Proc. AISTech2008, Vol. 2, AIST, Warrendale, PA, USA, (2008), 737.

6) K. Blazek, O. Lanzi and H. Yin: to be published in Proc. of AISTech 2009, Vol. 2, AIST, Warrendale, PA, USA, (2009), 631.

7) O. Kubaschewski: Iron-Binary Phase Diagrams, Springer-Verlag, Berlin, (1982), 16.

8) H. Chikama, H. Shibata, T. Emi and M. Suzuki: Mater. Trans. JIM, 37 (1996), 620.

9) L. Laus: ArcelorMittal Global R\&D_East Chicago Internal Report, (2008). 